\title{
Evaluation of Prophylaxis with Norfloxacin and Ceftriaxone versus Ciprofloxacin during the Period of Neutropenia after Haematopoietic Stem Cell Transplantation: Retrospective Analysis of Two Sequencial Cohorts
}

\author{
Valéria Paes Lima Fernandes¹, Paola Cappellano¹, Maria Daniela DiDea Bergamasco', \\ Janaína Midori Goto ${ }^{1}$, José Salvador Rodrigues de Oliveira², Carlos Alberto Pires Pereira1* \\ ${ }^{1}$ Discipline of Infectology-Federal University of São Paulo (UNIFESP), São Paulo, Brazil \\ ${ }^{2}$ Discipline of Haematology-Federal University of São Paulo (UNIFESP), São Paulo, Brazil \\ Email: valeriapaes@yahoo.com.br, pcappellano@uol.com.br, danididea@uol.com.br, janagoto@yahoo.com, \\ josesro@uol.com.br,
}

Received 5 March 2014; revised 5 April 2014; accepted 17 April 2014

Copyright (C) 2014 by authors and Scientific Research Publishing Inc.

This work is licensed under the Creative Commons Attribution International License (CC BY). http://creativecommons.org/licenses/by/4.0/

(c) $\underset{\mathrm{EY}}{\mathrm{E}}$ Open Access

\section{Abstract}

Background: The aim of this study was to evaluate the occurrence of febrile neutropenia (FN) during aplasia after haematopoietic stem cell transplantation (HSCT) in patients who received antibacterial prophylaxis with norfloxacin/ceftriaxone or ciprofloxacin, between September 2006 and May 2009. Methods: We retrospectively examined all patients undergoing HSCT at São Paulo Hospital during the study period. Results: Of the 107 studied patients, $71(66.3 \%)$ were included in the analysis. The exclusion criteria were as follows: occurrence of fever or infection before the transplantation (17), prophylactic use of norfloxacin (6), fever of probable non-infectious aetiology (2), and absence of prophylaxis during the aplasia period (11). Thirty-eight patients received norfloxacin and ceftriaxone as prophylaxis (Group I) and 33 received ciprofloxacin (Group II). The groups were comparable with respect to age, underlying diseases, comorbidities, and status of the underlying disease. Patients in Group II used antibiotics in a significantly higher frequency than those in Group I $(66.7 \%$ vs $33.8 \%$, $p=0.017)$, for 30 days before transplantation. The number of previous hospitalisations, length of hospitalisation until transplantation, type of transplant, progenitor cells used, number of $\mathrm{CD}_{34}$ cells infused, type of conditioning, and graft-versus-host disease

\footnotetext{
"Corresponding author.
}

How to cite this paper: Fernandes, V.P.L., et al. (2014) Evaluation of Prophylaxis with Norfloxacin and Ceftriaxone versus Ciprofloxacin during the Period of Neutropenia after Haematopoietic Stem Cell Transplantation: Retrospective Analysis of Two Sequencial Cohorts. Advances in Infectious Diseases, 4, 77-86. http://dx.doi.org/10.4236/aid.2014.42013 
prophylaxis were similar in both groups. After the transplantation, $28.9 \%$ and $39.4 \%$ of the patients in Groups I and II, respectively, presented Grade III and IV mucositis ( $p=0.448)$. Neutropenia of $<500$ neutrophils $/ \mathrm{mm}^{3}$ lasted an average of 9.5 and 9.3 days in Groups I and II, whereas neutropenia of $<100$ neutrophils $/ \mathrm{mm}^{3}$ lasted between 6.6 and 5.7 days. FN occurred in $78.9 \%$ of patients in Group I and $81.8 \%$ in Group II, with no significant difference in the classification of these episodes. Six patients (15.8\%) in Group I and five (15.2\%) in Group II had bacteraemia. All patients who did not receive prophylaxis developed FN. Conclusions: The high incidence and classification of FN episodes were similar between groups; however, the frequency was lower than in those patients who did not receive prophylaxis.

\title{
Keywords
}

\author{
Febrile Neutropenia, Prophylaxis, Haematopoietic Stem Cell Transplantation, Ciprofloxacin, \\ Ceftriaxone
}

\section{Background}

Infections are a major cause of morbidity and mortality in patients undergoing haematopoietic stem cell transplantation (HSCT), and the primary cause of death in $8.0 \%$ of patients undergoing autologous transplantation and in $17.0 \%-20.0 \%$ of those receiving allogeneic transplants [1]. The greatest risk occurs in the period after the conditioning regimen, during neutropenia. During this stage, bacterial infections are the most prevalent; however, fungal infections may also occur, especially Candida and Aspergillus infections. With rare exceptions, the incidence of infections is greatly reduced after this stage. In allogeneic HSCT, the risk remains high for at least a year [2].

Much has been learnt in recent years about "febrile neutropenia" (FN), which is essential in reducing transplant-related mortality. Nevertheless, the incidence of this condition remains very high [3]. In addition, patients undergoing HSCT have a higher risk of mortality than patients with low-risk FN, such as those undergoing treatment for solid tumours. Of these patients, $18.0 \%-40.0 \%$ present microbiological confirmation of infection with positive blood cultures [4]-[6].

For these reasons, there is a need for adopting preventive measures to reduce the occurrence of infections during the period of neutropenia. Several strategies have been investigated, including the use of prophylactic antibiotics during this period [7].

Quinolones (ciprofloxacin and levofloxacin) are the currently recommended antibiotics for prophylactic use, supported by meta-analysis studies that showed a significant reduction in risk of death associated with the use of prophylactic quinolones [7]-[13]. Meanwhile, a study evaluating levofloxacin versus placebo observed a significant reduction in the occurrence of fever, microbiologically documented infections, and gram-negative and polymicrobial bacteraemia; however, no impact on survival was observed [14].

Most of the patients included in these studies presented haematological disorders, with a smaller proportion of patients who had undergone HSCT. The recommendations used for neutropenic patients after chemotherapy were transferred to patients undergoing HSCT. The few clinical studies in transplanted patients indicate the benefits of this practice [15]-[17]. The objective of this study was to evaluate the occurrence of FN, during aplasia after HSCT, in patients who underwent antibacterial prophylaxis with norfloxacin/ceftriaxone or ciprofloxacin.

\section{Methods}

The study was conducted at Hospital São Paulo (HSP), a teaching hospital associated with the Federal University of São Paulo (UNIFESP). The haematology unit comprises 19 beds, of which seven are allocated for bone marrow transplantation. This research project was approved by the ethics committee of UNIFESP.

The study included all patients undergoing HSCT (autologous or allogeneic), performed between 1 September 2006, and 31 May 2009. Patients with one of the following criteria were excluded:

1). Fever or infection diagnosed before transplantation requiring treatment with systemic antibiotics during 
conditioning and/or infusion of haematopoietic stem cells;

2). Patients who did not use systemic antibacterial prophylaxis, or did so for a period $<48 \mathrm{~h}$ (four doses);

3). Patients who presented FN during the use of the norfloxacin for antibacterial prophylaxis after HSCT, and therefore, before the use of ceftriaxone; and

4). Patients who evolved with fever of probable non-infectious aetiology during the neutropenia period.

The protocol for use of antibacterial prophylaxis after HSCT is described below:

a) Between September 2006 and March 2008, 400 mg norfloxacin was used orally every $12 \mathrm{~h}$, starting with the conditioning regimen, followed by a replacement with $1 \mathrm{~g}$ ceftriaxone intravenously every $12 \mathrm{~h}$ when the neutrophils were $<1000$ cells $/ \mathrm{mm}^{3}$, maintained until a sustained recovery of bone marrow to $>1500$ total neutrophils (Group I).

b) Between April 2008 and May 2009, 500 mg ciprofloxacin was used orally every 12 h, starting with the conditioning regimen and maintained until the sustained recovery of bone marrow to $>1500$ total neutrophils. In case of severe mucositis or inability to use an oral antibiotic, the antibiotic was administered intravenously (Group II).

All evaluated patients used antifungal prophylaxis (fluconazole, 200 - $400 \mathrm{mg} /$ day) and antiviral prophylaxis (400 mg acyclovir taken orally every $12 \mathrm{~h}$ or $10 \mathrm{mg} / \mathrm{kg} / \mathrm{dose}$ intravenously).

The variables related to the patient characteristics, underlying diseases, transplantation and progress after the procedure, and outcomes were retrospectively analysed by evaluating the medical records and reviewing laboratory test results. In addition, the occurrence of FN and its classification (FUO-fever of unknown origin, MDI-microbiologically documented infection, CDI—clinically documented infection), death, or hospital discharge were evaluated.

The collected data were stored in a database, using Excel 2007 for Windows. Analyses were performed using the PASW Statistics v.18 package. The chi-square test was used to evaluate possible associations between variables. Fisher's exact test was applied for $2 \times 2$ tables. Student's t-test (two groups) was used for comparisons between means of quantitative variables in each group. The statistical significance level was set at $5.0 \%(\mathrm{p}<$ $0.05)$.

\section{Results}

During the study period, 107 patients were consecutively submitted to HSCT. Among them, 71 (66.3\%) were included in the study, of whom 38 (35.5\%) received norfloxacin and ceftriaxone (Group I) and 33 (30.6\%) received ciprofloxacin (Group II) as antibacterial prophylaxis. Thirty-three (33.7\%) patients were excluded, most because of fever and/or infection before HSCT infusion (Figure 1). Eleven patients (10.3\%) did not receive any antibiotic prophylaxis owing to failure in the protocol.

The two groups were similar with respect to the mean and median age; however, a higher proportion of women were observed among those who received ciprofloxacin, although no statistical significance was found (Table 1).

Group I was mainly composed of patients with multiple myeloma as the underlying disease (47.3\%), whereas only $27.3 \%$ presented this diagnosis in Group II. In the Group II, the percentage of patients with acute leukaemia was higher than in Group I. Nevertheless, the groups were statistically similar with respect to underlying diseases and the "status" of the underlying disease. Comorbidities were present in $36.8 \%$ and $45.5 \%$ of the patients in Groups I and II, respectively (without significant differences).

Hospitalisation within 30 days before HSCT occurred in $23.6 \%$ and $33.3 \%$ of patients in Groups I and II, respectively; these hospitalisations occurred mainly for mobilisation and the treatment of infections related to previous chemotherapies. The number of hospitalisation days until the infusion of stem cells was also similar in the two groups.

In Group I, 36.8\% (14 of 38) received systemic antibiotics within the 30 days before the infusion of stem cells; eight patients received quinolones (ciprofloxacin or levofloxacin), and six patients were treated with cephalosporins. In Group II, 66.7\% (22 of 33) were exposed; this represented a statistical difference between the groups ( $\mathrm{p}=0.017)$. In Group II, 20 patients were treated with quinolones, and 2 patients with cephalosporins.

In Group I, only one patient started using ciprofloxacin for prophylactic purposes (replaced by ceftriaxone during the period of aplasia) before the beginning of the conditioning chemotherapy. In Group II, eight patients received ciprofloxacin prophylaxis, during 2 - 13 days, before the beginning of the conditioning chemotherapy, 


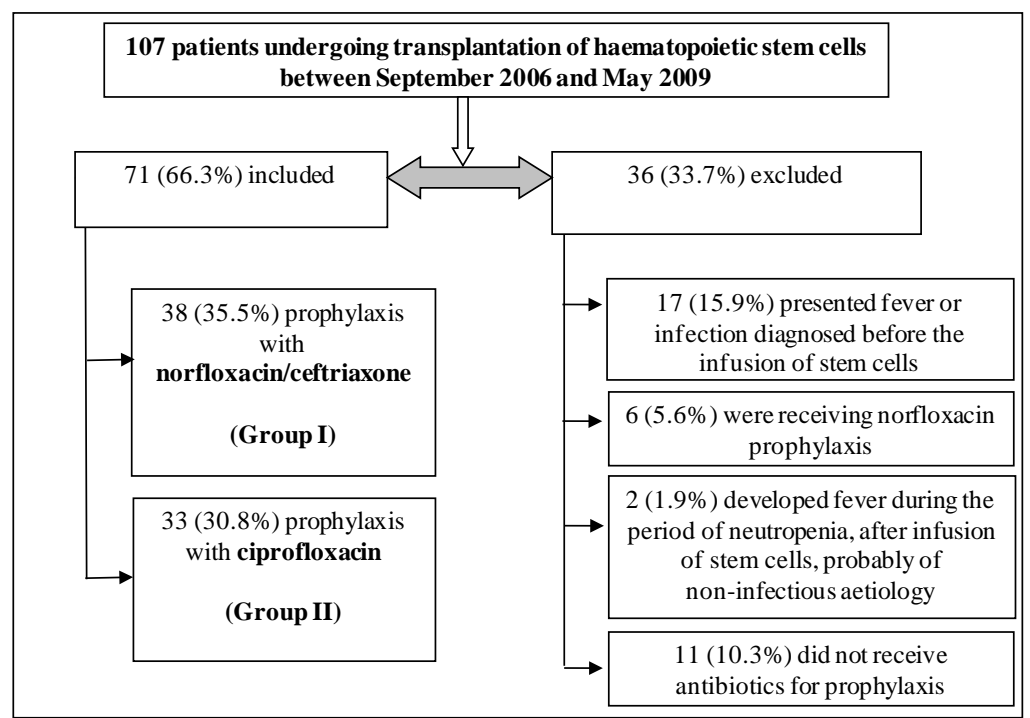

Figure 1. Flowchart showing the distribution of patients who underwent haematopoietic stem cell transplantation (HSCT), at Hospital São Paulo, according to the prophylaxis used and exclusion criteria.

Table 1. Characteristics of the patients undergoing haematopoietic stem cell transplantation.

\begin{tabular}{|c|c|c|c|c|}
\hline \multirow{2}{*}{\multicolumn{2}{|c|}{ Variables }} & Group I $(n=38)$ & Group II $(n=33)$ & \multirow{2}{*}{$\mathbf{p}$} \\
\hline & & n (\%) & $\mathrm{n}(\%)$ & \\
\hline \multicolumn{5}{|l|}{ Age } \\
\hline & Mean \pm standard deviation & $46.6 \pm 2.1$ & $45.1 \pm 2.0$ & \multirow[t]{3}{*}{$n s$} \\
\hline & Median & 49 & 47 & \\
\hline & Interval & $17-69$ & $22-64$ & \\
\hline \multicolumn{5}{|l|}{ Sex } \\
\hline & Male & $20(52.6)$ & $13(39.4)$ & \multirow{2}{*}{$n s$} \\
\hline & Female & $18(47.4)$ & $20(60.6)$ & \\
\hline \multicolumn{5}{|l|}{ Underlying diseases } \\
\hline & Acute leukaemia & $7(18.4)$ & $8(24.2)$ & \multirow{6}{*}{$n s$} \\
\hline & Chronic Leukaemia & 0 & $2(6.1)$ & \\
\hline & Non-Hodgkin lymphoma & $8(21.1)$ & $8(24.2)$ & \\
\hline & Hodgkin lymphoma & $5(13.2)$ & $3(9.1)$ & \\
\hline & Multiple myeloma & $18(47.4)$ & $9(27.3)$ & \\
\hline & Other & 0 & $3(9.1)$ & \\
\hline Hospitalisation (<30 days) & & $9(23.7)$ & $11(33.3)$ & $n s$ \\
\hline Antibiotics (<30 days) & & $14(36.8)$ & $22(66.7)$ & 0.017 \\
\hline \multicolumn{5}{|l|}{ Type of transplant } \\
\hline & Autologous & 31 (81.6) & $21(63.6)$ & \multirow[t]{2}{*}{$n s$} \\
\hline & Allogeneic & $7(18.4)$ & $12(36.4)$ & \\
\hline \multicolumn{5}{|l|}{ Progenitor cells } \\
\hline & Peripheral blood & $33(86.8)$ & $28(84.8)$ & \multirow[t]{2}{*}{ ns } \\
\hline & Bone marrow & $5(13.2)$ & $5(15.2)$ & \\
\hline \multicolumn{5}{|l|}{ Conditioning regimen ${ }^{1}$} \\
\hline & Melphalan & $17(44.7)$ & $8(24.3)$ & \multirow[t]{6}{*}{ ns } \\
\hline & BEAM & $12(31.6)$ & $11(33.4)$ & \\
\hline & Cyclophosphamide + TBI & $2(5.3)$ & $2(6.0)$ & \\
\hline & Fludarabine + TBI & $2(5.3)$ & $4(12.1)$ & \\
\hline & Busulfan + Cyclophosphamide & $4(10.5)$ & $4(12.1)$ & \\
\hline & Others & $1(2.6)$ & $4(12.1)$ & \\
\hline
\end{tabular}

\footnotetext{
${ }^{1}$ Abbreviations of the conditioning regimen: BEAM = BCNU (carmustine) + etoposide + cytarabine + melphalan; $\mathrm{TBI}$ = total body irradiation .
} 
as opposed to the recommended protocol. Two patients presented symptoms compatible with allergic reaction to ciprofloxacin.

The groups were similar in the statistical analysis for the type of transplant, progenitor cells used, number of $\mathrm{CD}_{34}$ cells infused, type of conditioning, and graft-versus-host disease prophylaxis. Among those who received allogeneic transplants, two patients in Group I and five patients in Group II received non-myeloablative conditioning.

The groups were similar with respect to the occurrence of grade III and IV mucositis, use of parenteral nutrition, and duration of neutropenia. The mean duration of neutropenia of $<500$ neutrophils/mm ${ }^{3}$ in Group I was 9.5 days with a median of 8 days ( 1 - 44 days); Group II showed a mean of 9.3 days and median of 8 days (0 27 days). The duration of neutropenia of $<100$ neutrophils $/ \mathrm{mm}^{3}$ was 6.6 days with a median of 6 days (0 - 28 days) in Group I, and 5.7 days with a median of 5 days (0 - 23 days) in Group II. There was no statistical difference between the groups in the duration of neutropenia. The number of days of neutropenia until the occurrence of fever, and the total hospitalisation period in the evolution after HSCT were also similar between the groups. A greater proportion of patients in Group I used granulocyte colony-stimulating factor (G-CSF) $(p=0.051)$, and the duration of use of G-CSF was significantly higher $(p=0.036)$ in Group I $(11.2 \pm 0.9$ days) than in Group II (8.82 \pm 0.5 days).

FN occurred at a high frequency, 78.9\% (30 of 38) in Group I and 81.8\% (27 of 33) in Group II, but with no statistically significant differences. This was the main reason for discontinuation of antibacterial prophylaxis and its replacement with a broad-spectrum antibiotic (Table 2).

The most frequent MDI was bacteraemia, followed by urinary tract infection and infection at the site of insertion of the central catheter. Bacterial agents identified in clinical specimens collected during neutropenia are described in Table 3. Abdominal infections were the most frequent ICD (typhlitis) with one case in Group I and three in Group II.

There were five deaths among the patients included in the study: four in Group I and one in Group II. However, only one death from Group I occurred during the period of neutropenia, associated with a bloodstream polymicrobial infection by Enterococcus spp. and an unidentified non-fermenter gram negative bacillus, at D+10. The other three deaths occurred at a later stage (D+25, D+35, and D+68). The death in Group II occurred at $\mathrm{D}+11$ with a suspected neutropenic enterocolitis as the primary cause, complicated by an E. coli producing extended-spectrum $\beta$-lactamase superinfection. Therefore, one patient died of primary infectious cause during neutropenia in each group ( $\mathrm{p}=0.363)$.

The antibiotic prophylaxis was kept unmodified in 14 patients: eight in Group I and six in Group II. The total duration of prophylaxis in Group I was 7 - 25 days with a mean of 12.9 days and a median of 11.5 days, and in Group II, it ranged from 4 to 36 days, with an average of 13 days and a median of 16 days, with no statistically significant difference between the groups.

Seventeen patients were excluded from the study because of the occurrence of fever or infection diagnosed before the infusion of haematopoietic stem cells. These patients received broad-spectrum antibiotics at the time of transplantation, for the treatment of proven or clinically diagnosed infections, mostly by hospital microbiota. Most of these patients (12 of 17, 70.6\%) underwent allogeneic transplantation, including two cases of non-related HLA-compatible donor. Six patients (35.3\%) died.

Six patients destinated to norfloxacin/ceftriaxone prophylaxis presented FN after HSCT during the use of norfloxacin. The classification of the febrile episode was FUO in $66.7 \%$ (4 of 6), MDI in 16.7\% (1 of 6, subclassified as bacteraemia), and ICD in 16.7\% (1 of 6) with an abdominal focus. One patient died in this group due to concomitant pulmonary infection by a respiratory syncytial virus.

Two patients were excluded because they developed, in the period of aplasia, fever of non-infectious aetiology, associated with infusion of blood products. Both patients were treated with cefepime until recovery from neutropenia and presented good outcomes.

Eleven patients did not receive antibiotic prophylaxis during the period of aplasia. All patients developed fever or infection diagnosed during the period of neutropenia, classified as FUO in $18.2 \%$ (2 of 11), ICD in 18.2\% (2 of 11), and MDI in 63.6\% (7 of 11). Six patients presented bacteraemia (54.5\%) and one patient had a urinary tract infection (9.1\%). Three patients died in this group (27.3\%), but only one of them during neutropenia, at $\mathrm{D}+7$, due to typhlitis with secondary bacteraemia caused by E. coli resistant to quinolones. The other deaths occurred in a later stage, at D+29 and D+38. 
Table 2. Occurrence of febrile neutropenia during the aplasia period in patients transplantated with haematopoietic stem cells.

\begin{tabular}{|c|c|c|c|}
\hline \multirow{2}{*}{ Variables } & Group I $(n=38)$ & Group II (n = 33) & \multirow{2}{*}{$\mathbf{p}$} \\
\hline & n (\%) & n (\%) & \\
\hline Febrile neutropenia & $30(78.9)$ & $27(81.8)$ & $n s$ \\
\hline \multicolumn{4}{|l|}{ Classification } \\
\hline Fever of unknown origin & $19(50.0)$ & $14(42.4)$ & $n s$ \\
\hline Documented infections ${ }^{1}$ & $11(28.9)$ & $13(39.4)$ & ns \\
\hline Microbiologically documented infections & $8(21.0)$ & $8(24.2)$ & \\
\hline Bacteraemia & $6(15.8)$ & $5(15.2)$ & \\
\hline Polymicrobial bacteraemia & $2(5.3)$ & $1(3.0)$ & \\
\hline Urinary tract infection & $1(2.6)$ & $2(6.1)$ & \\
\hline Infection of the catheter insertion site & $1(2.6)$ & $1(3.0)$ & \\
\hline Clinically documented infections & $3(7.9)$ & $5(15.2)$ & \\
\hline
\end{tabular}

${ }^{1}$ Total clinically or microbiologically documented infections.

Table 3. Bacterial agents identified in clinical specimens collected during neutropenia.

\begin{tabular}{|c|c|c|}
\hline & & Group I \\
\hline \multicolumn{3}{|c|}{ Blood stream infections } \\
\hline 1 & Blood culture (D+6) & Enterococcus spp. + unidentified non-fermenter gram negative bacillus \\
\hline 2 & Blood culture (D+6) & Coagulase-negative Staphylococcus \\
\hline 3 & Blood culture (D+7) & Coagulase-negative Staphylococcus \\
\hline 4 & Blood culture (D+7) & Acinetobacter baumanii \\
\hline 5 & Blood culture (D+10) & Staphylococcus epidermidis \\
\hline 6 & Blood culture (D+4) & Coagulase-negative Staphylococcus + Pseudomonas putida \\
\hline \multicolumn{3}{|c|}{ Other microbiologically documented infection } \\
\hline 7 & Urine $(\mathrm{D}+5)$ & Klebsiella pneumoniae ESBL \\
\hline 8 & $\begin{array}{l}\text { Catheter tip and catheter insertion secretion } \\
\qquad(\mathrm{D}+11)\end{array}$ & Acinetobacter baumanii MR + Stenotrophomonas maltophilia \\
\hline \multicolumn{3}{|r|}{ Group II } \\
\hline \multicolumn{3}{|c|}{ Blood stream infections } \\
\hline 9 & Blood culture (D+6) & Klebsiella pneumoniae \\
\hline 10 & Blood culture $(\mathrm{D}+10)$ & Enterobacter cloacae + Escherichia coli \\
\hline 11 & Blood culture (D+4) & Acinetobacter baumanii \\
\hline 12 & Blood culture $(\mathrm{D}+6)$ & Coagulase-negative Staphylococcus \\
\hline 13 & Blood culture (D+3) & Micrococcus spp. \\
\hline \multicolumn{3}{|c|}{ Other microbiologically documented infection } \\
\hline 14 & Urine (D+7) & Escherichia coli \\
\hline 15 & Urine (D+5) & Escherichia coli \\
\hline 16 & Catheter tip (D+11) & Coagulase-negative Staphylococcus \\
\hline
\end{tabular}

\section{Discussion}

The use of antibiotic prophylaxis for the prevention of FN and death is an established practice in high-risk onco-haematological patients. It is also used in patients undergoing HSCT. In this study, we compared two prophylaxis regimens (norfloxacin/ceftriaxone vs ciprofloxacin) and found no statistically significant differences in the occurrence of FN between treatments. 
It is important to consider that the temporal distribution of patients in Groups I and II diverged-Group I patients underwent HSCT between the years 2006 and 2007, whereas patients in Group II underwent HSCT between in 2008 and 2009. This fact is important when considering the hospital microbiota and aspects in the clinical practice of the medical and nursing teams that might be not directly evaluable because they change over time.

The variation of the underlying diseases in the two groups, although not statistically significant, is relevant. Patients in Group II presented a higher proportion of acute leukaemias, chronic leukaemias, and other diagnoses-aplastic anaemia, myelodysplasia, and solid tumours (one case of each of these diagnoses) - indicating greater diversification of the therapeutic use of HSCT at HSP. The higher number of allogeneic non-myeloablative conditioning transplants, transplants with stem cells from cord blood, and two unrelated transplants (with HLA compatibility) in Group II is also relevant. These differences were not significant, probably owing to the number of cases included in the analysis; however, they reflect an increased team expertise and could have influenced the observed outcomes.

The proportion of patients who used systemic antimicrobials in the 30 days before the infusion of haematopoietic stem cells was significantly higher in Group II than in Group I, which could lead to increased bacterial resistance. However, this variable did not appear to influence the outcome in the present study.

A greater proportion of patients in Group I used granulocyte-monocyte colony stimulating factor; the mean duration of use was statistically significantly different between the two groups (11.2 days in Group I and 8.8 days in Group II, $\mathrm{p}=0.036$ ). It is likely that this difference is due to the greater number of autologous transplants performed in Group I and to the underlying diseases of the patients compared with Group II.

A high occurrence of FN was observed (78.5\% in Group I and 81.8\% in Group II). Other studies in patients undergoing HSCT and in the use of antibiotic prophylaxis also showed a high incidence of FN (53.0\% - 98.0\%) with different prophylactic schemes [15]-[22]. Despite this, we observed better outcomes in patients who received than in those who did not receive prophylactic antibiotics. No difference between the groups that used prophylaxis was observed concerning the type of infectious process presented.

The antibiotics ceftriaxone and ciprofloxacin, although being from different therapeutic classes, have a common spectrum of good activity for most enterobacteria. However, it is important to consider that ciprofloxacin, unlike ceftriaxone, has good activity against Pseudomonas spp. This agent is associated with high mortality in febrile neutropenic patients [9].

Considering that the damage in the intestinal epithelium, induced by the cytotoxic chemotherapy, is usually the first event in the pathogenesis of infection in neutropenic patients [23], it is inferred that the prevalence of enterobacteria resistant to prophylactic antibiotics may influence the efficacy of the prophylaxis. Recent studies conducted in São Paulo and other locations, in patients with urinary tract infection, showed that the prevalence of resistance to ciprofloxacin is greater than that to ceftriaxone $(11.9 \%$ vs $0.3 \%)$; however, there are no specific data in onco-haematological patients [24].

Guthrie and colleagues compared the use of ceftazidime with levofloxacin for prophylaxis during aplasia in patients undergoing allogeneic HSCT and observed a higher occurrence of FN when using the quinolone. However, the lower incidence of bacteraemia until the 100th day after HSCT, the lowest acquisition cost of levofloxacin, and the lack of detection of significant adverse side effects from the use of this prophylaxis led the authors to keep quinolone as the recommended drug for prophylactic use in patients undergoing allogeneic HSCT [20].

It should be noted that even in studies that used broad-spectrum antibiotics such as meropenem [16] and piperacillin-tazobactam [19] as prophylaxis, FN occurred in about $76.0 \%$ of patients, similar to that observed in this study. This indicates that the use of antimicrobials is not enough to contain the infectious risks posed by the underlying disease and the transplantation procedure itself.

Besides these aspects, other consequences from the use of prophylaxis may alter the cost-effectiveness of this practice, such as the sensitivity profiles of causative agents of escape infections, the probability of clinical responses to antibiotics used empirically in this situation, and the occurrence of pseudomembranous colitis. The prescription of the appropriate empirical treatment in FN is essential to prevent deaths [25].

Of the 14 patients followed during prophylaxis and who did not present FN, none showed grade III or IV mucositis. Moreover, the average time of neutropenia of $<100$ cells $/ \mathrm{mm}^{3}$ in these patients tended to be lower than the observed mean in their respective groups, as well as the average time of neutropenia of $<500$ cells $/ \mathrm{mm}^{3}$ in patients in Group I. These patients were therefore less exposed to two major risk factors for FN. Therefore, it 
is questionable if the absence of FN can be attributed to the use of antibacterial prophylaxis. As was observed by Facchini, it is possible that the chance of infection increases proportionally with the number of risk factors [26].

The most appropriate approach would be a clinical trial specifically designed to better define the role of bacterial prophylaxis, considering the individual risks of each patient and the multiple factors involved in the pathogenesis of infections in this context.

About one-third of the patients undergoing HSCT during the study period showed some of the exclusion criteria. Most were excluded because of the occurrence of fever or infection before the infusion of haematopoietic stem cells. This is in agreement with the literature data demonstrating increased risk for bacterial infections in this population [5] [10]. These patients have become ineligible for the use of bacterial prophylaxis because the same infectious episode occurred before the transplantation itself, and showed a high mortality rate.

Six patients who were indicated for prophylactic use of ceftriaxone developed fever even when they were using norfloxacin, which can be considered a disadvantage of this prophylaxis strategy. A comparative study showed a lower efficacy of norfloxacin in preventing infectious outcomes compared with ciprofloxacin, and for this reason, these patients were excluded from the evaluation [27].

Of the 11 patients who did not use prophylaxis, all (100\%) presented FN in the immediate post-transplant period. The occurrence of bacteraemia in six (54.5\%) patients in this group was also significant, as this type of infection has a greater risk of death. Thus, despite the small number of patients and the high frequency of FN in those who also used prophylaxis, it can be inferred that the antibiotic demonstrated a protective role.

No statistical difference was observed in the occurrence of deaths from infectious primary cause between Groups I and II. Only one death with infection as the primary cause occurred in the group of patients who did not receive prophylaxis, not allowing conclusions in this regard.

\section{Competing Interests}

The authors declare that there is no conflict of interest.

\section{References}

[1] Tomblyn, M., Chiller, T., Einsele, H., Gress, R., Sepkowitz, K., Storek, J., Wingard, J.R., Young, J.A. and Boeckh, M.J. (2009) Guidelines for Preventing Infectious Complications among Hematopoietic Cell Transplant Recipients: A Global Perspective. Preface. Bone Marrow Transplant, 44, 453-455. http://dx.doi.orgdoi: /10.1038/bmt.2009.254

[2] Kruger, W., Rüssmann, B., Kröger, N., Salomon, C., Ekopf, N., Elsner, H.A., Kaulfers, P.M., Mack, D., Fuchs, N., Dürken, M., Kabisch, H., Erttmann, R. and Zander, A.R. (1999) Early Infections in Patients Undergoing Bone Marrow or Blood Stem Cell Transplantation-A 7 Year Single Centre Investigation of 409 Cases. Bone Marrow Transplant, 23, 589-597. http://dx.doi.org/10.1038/sj.bmt.1701614

[3] Viscoli, C., Varnier, O. and Machetti, M. (2005) Infections in Patients with Febrile Neutropenia: Epidemiology, Microbiology, and Risk Stratification. Clinical Infectious Diseases, 40, S240-S245. http://dx.doi.org/10.1086/427329

[4] Collin, B.A., Leather, H.L., Wingard, J.R. and Ramphal, R. (2001) Evolution, Incidence, and Susceptibility of Bacterial Bloodstream Isolates from 519 Bone Marrow Transplant Patients. Clinical Infectious Diseases, 33, 947-953. http://dx.doi.org/10.1086/322604

[5] Mendes, E.T., Dulley, F., Basso, M., Batista, M.V., Coracin, F., Guimarães, T., Shikanai-Yasuda, M.A., Levin, A.S. and Costa, S.F. (2012) Healthcare-Associated Infection in Hematopoietic Stem Cell Transplantation Patients: Risk Factors and Impact on Outcome. International Journal of Infectious Diseases, 16, E424-E428. http://dx.doi.org/10.1016/j.ijid.2012.01.015

[6] Oliveira, A.L., de Souza, M., Carvalho-Dias, V.M., Ruiz, M.A., Silla, L., Tanaka, P.Y., Simões, B.P., Trabasso, P., Seber, A., Lotfi, C.J., Zanichelli, M.A., Araujo, V.R., Godoy, C., Maiolino, A., Urakawa, P., Cunha, C.A., de Souza, C.A., Pasquini, R. and Nucci, M. (2007) Epidemiology of Bacteremia and Factors Associated with Multi-Drug-Resistant Gram-Negative Bacteremia in Hematopoietic Stem Cell Transplant Recipients. Bone Marrow Transplant, 39, 775781. http://dx.doi.org/10.1038/sj.bmt.1705677

[7] Viscoli, C. (2007) Antibacterial Prophylaxis in Neutropenic Patients. International Journal of Antimicrobial Agents, 30, S60-S65. http://dx.doi.org/10.1016/j.ijantimicag.2007.06.016

[8] Flowers, C.R., Seidenfeld, J., Bow, E.J., Karten, C., Gleason, C., Hawley, D.K., Kuderer, N.M., Langston, A.A., Marr, K.A., Rolston, K.V. and Ramsey, S.D. (2013) Antimicrobial Prophylaxis and Outpatient Management of Fever and Neutropenia in Adults Treated for Malignancy: American Society of Clinical Oncology Clinical Practice Guideline. Journal of Clinical Oncology, 31, 794-810. http://dx.doi.org/10.1200/JCO.2012.45.8661 
[9] Freifeld, A.G., Bow, E.J., Sepkowitz, K.A., Boeckh, M.J., Ito, J.I., Mullen, C.A., Raad, I.I., Rolston, K.V., Young, J.A. and Wingard, J.R. (2011) Clinical Practice Guideline for the Use of Antimicrobial Agents in Neutropenic Patients with Cancer: 2010 Update by the Infectious Diseases Society of America. Clinical Infectious Diseases, 52, E56-E93. http://dx.doi.org/10.1093/cid/cir073

[10] Tomblyn, M., Chiller, T., Einsele, H., Gress, R., Sepkowitz, K., Storek, J., Wingard, J.R., Young, J.A. and Boeckh, M.J. (2009) Guidelines for Preventing Infectious Complications among Hematopoietic Cell Transplantation Recipients: A Global Perspective. Biology of Blood and Marrow Transplantation, 15, 1143-1238. http://dx.doi.org/10.1016/j.bbmt.2009.06.019

[11] van de Wetering, M.D., de Witte, M.A., Kremer, L.C., Offringa, M., Scholten, R.J. and Caron, H.N. (2005) Efficacy of Oral Prophylactic Antibiotics in Neutropenic Afebrile Oncology Patients: A Systematic Review of Randomised Controlled Trials. European Journal of Cancer, 41, 1372-1382. http://dx.doi.org/10.1016/j.ejca.2005.03.006

[12] Gafter-Gvili, A., Fraser, A., Paul, M. and Leibovici, L. (2005) Meta-Analysis: Antibiotic Prophylaxis Reduces Mortality in Neutropenic Patients. Annals of Internal Medicine, 142, 979-995. http://dx.doi.org/10.7326/0003-4819-142-12_Part_1-200506210-00008

[13] Gafter-Gvili, A., Fraser, A., Paul, M., Vidal, L., Lawrie, T.A., van de Wetering, M.D., Kremer, L.C. and Leibovici, L. (2005) Antibiotic Prophylaxis for Bacterial Infections in Afebrile Neutropenic Patients Following Chemotherapy. The Cochrane Database of Systematic Reviews, Article ID: CD004386. http://dx.doi.org/10.1002/14651858.CD004386.pub3

[14] Bucaneve, G., Micozzi, A., Menichetti, F., Martino, P., Dionisi, M.S., Martinelli, G., Allione, B., D’Antonio, D., Buelli, M., Nosari, A.M., Cilloni, D., Zuffa, E., Cantaffa, R., Specchia, G., Amadori, S., Fabbiano, F., Deliliers, G.L., Lauria, F., Foà, R. and Del Favero, A. (2005) Levofloxacin to Prevent Bacterial Infection in Patients with Cancer and Neutropenia. The New England Journal of Medicine, 353, 977-987. http://dx.doi.org/10.1056/NEJMoa044097

[15] Lew, M.A., Kehoe, K., Ritz, J., Antman, K.H., Nadler, L., Takvorian, T., Mayer, R., Kalish, L. and Finberg, R. (1991) Prophylaxis of Bacterial Infections with Ciprofloxacin in Patients Undergoing Bone Marrow Transplantation. Transplantation, 51, 630-636. http://dx.doi.org/10.1097/00007890-199103000-00017

[16] Perez-Simon, J.A., García-Escobar, I., Martinez, J., Vazquez, L., Caballero, D., Cañizo, C., Mateos, M.V. and San Miguel, J.F. (2004) Antibiotic Prophylaxis with Meropenem after Allogeneic Stem Cell Transplantation. Bone Marrow Transplantation, 33, 183-187. http://dx.doi.org/10.1038/sj.bmt.1704335

[17] Eleutherakis-Papaiakovou, E., Kostis, E., Migkou, M., Christoulas, D., Terpos, E., Gavriatopoulou, M., Roussou, M., Bournakis, E., Kastritis, E., Efstathiou, E., Dimopoulos, M.A. and Papadimitriou, C.A. (2010) Prophylactic Antibiotics for the Prevention of Neutropenic Fever in Patients Undergoing Autologous Stem-Cell Transplantation: Results of a Single Institution, Randomized Phase 2 Trial. American Journal of Hematology, 85, 863-867. http://dx.doi.org/10.1002/ajh.21855

[18] Fernandez-Aviles, F., Carreras, E., Urbano-Ispizua, A., Rovira, M., Martínez, C., Gaya, A., Granell, M., Ramiro, L., Gallego, C., Hernando, A., Segura, S., García, L., González, M., Valverde, M. and Montserrat, E. (2006) Case-Control Comparison of At-Home to Total Hospital Care for Autologous Stem-Cell Transplantation for Hematologic Malignancies. Journal of Clinical Oncology, 24, 4855-4861. http://dx.doi.org/10.1200/JCO.2006.06.4238

[19] Solano, C., Gutierrez, A., Martinez, F., Gimeno, C., Gómez, C., Muñoz, I., Faus, F., Goterris, R., Farga, A. and Navarro, D. (2005) Prophylaxis of Early Bacterial Infections after Autologous Peripheral Blood Stem Cell Transplantation (PBSCT): A Matched-Pair Study Comparing Oral Fluoroquinolones and Intravenous Piperacillin-Tazobactam. Bone Marrow Transplantation, 36, 59-65. http://dx.doi.org/10.1038/sj.bmt.1705005

[20] Guthrie, K.A., Yong, M., Frieze, D., Corey, L. and Fredricks, D.N. (2010) The Impact of a Change in Antibacterial Prophylaxis from Ceftazidime to Levofloxacin in Allogeneic Hematopoietic Cell Transplantation. Bone Marrow Transplantation, 45, 675-681. http://dx.doi.org/10.1038/bmt.2009.216

[21] Sohn, B.S., Yoon, D.H., Kim, S., Lee, K., Kang, E.H., Park, J.S., Lee, D.H., Kim, S.H., Huh, J. and Suh, C. (2012) The Role of Prophylactic Antimicrobials during Autologous Stem Cell Transplantation: A Single-Center Experience. European Journal of Clinical Microbiology \& Infectious Diseases, 31, 1653-1661. http://dx.doi.org/10.1007/s10096-011-1489-2

[22] Vehreschild, J.J., Moritz, G., Vehreschild, M.J., Arenz, D., Mahne, M., Bredenfeld, H., Chemnitz, J., Klein, F., Cremer, B., Böll, B., Kaul, I., Wassmer, G., Hallek, M., Scheid, C. and Cornely, O.A. (2012) Efficacy and Safety of Moxifloxacin as Antibacterial Prophylaxis for Patients Receiving Autologous Haematopoietic Stem Cell Transplantation: A Randomised Trial. International Journal of Antimicrobial Agents, 39, 130-134. http://dx.doi.org/10.1016/j.ijantimicag.2011.10.009

[23] Urabe, A. (2004) Clinical Features of the Neutropenic Host: Definitions and Initial Evaluation. Clinical Infectious Diseases, 39, S53-S55. http://dx.doi.org/10.1086/383055

[24] Kiffer, C.R., Mendes, C., Oplustil, C.P. and Sampaio, J.L. (2007) Antibiotic Resistance and Trend of Urinary Patho- 
gens in General Outpatients from a Major Urban City. International Braz J Urol: Official Journal of Brazilian Society of Urology (Int Braz J Urol), 33, 42-48.

http://dx.doi.org/10.1590/S1677-55382007000100007

[25] Leibovici, L., Paul, M., Cullen, M., Bucaneve, G., Gafter-Gvili, A., Fraser, A. and Kern, W.V. (2006) Antibiotic Prophylaxis in Neutropenic Patients: New Evidence, Practical Decisions. Cancer, 107, 1743-1751. http://dx.doi.org/10.1002/cncr.22205

[26] Facchini, L., Martino, R., Ferrari, A., Piñana, J.L., Valcárcel, D., Barba, P., Granell, M., Delgado, J., Briones, J., Sureda, A., Brunet, S. and Sierra, J. (2012) Degree of Mucositis and Duration of Neutropenia Are the Major Risk Factors for Early Post-Transplant Febrile Neutropenia and Severe Bacterial Infections after Reduced-Intensity Conditioning. European Journal of Haematology, 88, 46-51. http://dx.doi.org/10.1111/j.1600-0609.2011.01724.x

[27] (1991) Prevention of Bacterial Infection in Neutropenic Patients with Hematologic Malignancies. A Randomized, Multicenter Trial Comparing Norfloxacin with Ciprofloxacin. The GIMEMA Infection Program. Gruppo Italiano Malattie Ematologiche Maligne dell'Adulto. Annals of Internal Medicine, 115, 7-12.

http://dx.doi.org/10.7326/0003-4819-115-1-7

\section{List of Abreviations}

FN: Febrile Neutropenia; HSCT: Haematopoietic Stem Cell Transplantation; FUO: Fever of Unknown Origin; MDI: Microbiologically Documented Infection; CDI: Clinically Documented Infection. 